\title{
EXAME REPRODUTIVO EM GATO-DO-MATO-PEQUENO (Leopardus tigrinus Schreber, 1775)
}

\author{
(Andrologic examination in small cat a mount (Leopardus tigrinus Schreber, 1775)
}

\author{
ERDMANN, R.H. ${ }^{1}$ JUVENAL, J.C. ${ }^{2}$; MORAES, W. ${ }^{2}$; CUBAS, P. ${ }^{2}$; CARVALHO, A.L. ${ }^{3}$; MOREIRA, N. ${ }^{4}$ \\ 'Medicina veterinária, PUC - Campus Toledo, Toledo - PR. Curso de pós-graduação em clinica e cirurgia \\ de animais selvagens - PUCPR, São José dos Pinhais - PR. Curso de pós-graduação em ciências \\ veterinárias, UFPR, Curitiba-PR; \\ ${ }^{2}$ ITAIPU Binacional - Foz do Iguaçu-PR; \\ ${ }^{3}$ Acadêmico do curso de medicina veterinária, UFPR - Campus Palotina, Palotina-PR; \\ ${ }^{4}$ Curso de pós-graduação em ciências veterinárias, UFPR, Curitiba-PR.
}

RESUMO - O objetivo desta pesquisa foi obter melhor compreensão da fisiologia reprodutiva dos pequenos felídeos neotropicais, necessária para um desempenho reprodutivo mais consistente em cativeiro e aumentar o número de indivíduos que se reproduzem na população cativa. Foram realizadas três séries de exames reprodutivos ( $n=32$ ) em 11 gatos-do-mato-pequeno (Leopardus tigrinus), mantidos em cativeiro no Criadouro de Animais Silvestres da Itaipu Binacional, em Foz do Iguaçu - PR. Os animais estavam alojados em recintos ambientados e eram alimentados com carne bovina, frango, pintainhos, ratos e suplemento mineral/vitamínico. O protocolo anestésico utilizado foi a associação de cloridrato de xilazina e cloridrato de tiletamina/zolazepan nas doses médias de 0,95 mg/Kg e 6,7 mg/kg, respectivamente. Os animais foram submetidos à colheita de sêmen pelo método de eletroejaculação conforme protocolo descrito por HOWARD (1986) com 8 séries de 10 estímulos, variando a intensidade de 2 a 5 Volts. Houve contaminação por urina em 10 colheitas (31,2\%), sendo possível desprezar as alíquotas contaminadas, com aproveitamento do restante da amostra. O volume médio obtido foi de $0,13 \pm 0,20 \mathrm{ml}$, com motilidade média de $73,44 \pm 3,71 \%$ e vigor de $3,48 \pm 0,11$. O pH médio foi 7,58 \pm 0,07. A concentração espermática foi de $436,41 \pm 95,8 \times 10^{6}$ espermatozóides $/ \mathrm{ml}$, sendo que a porcentagem média de espermatozóides morfologicamente normais foi de 55,86 $\pm 3,34 \%$. Os valores obtidos nesta amostragem são compatíveis com os descritos por outros autores, contribuindo assim, na formação de um banco de dados de características reprodutivas, para felídeos desta espécie mantidos em cativeiro.

Palvras-chaves: Sêmen, felideos, felinos, exame andrológico, Leopardus tigrinus.

ABSTRACT - A better understanding of the reproductive physiology of Neotropical small felids is necessary to get a more consistent reproductive performance aiming to increase the number of individuals that reproduce in the captive population and to develop and use assisted reproduction techniques. Andrologic examinations ( $n=32$ ) were performed in three series of captive small catamounts (Leopardus tigrinus, $n=11$ ), at Itaipu Binacional Wildlife Breeding Center, at Foz do Iguassu - PR - Brazil. Animals were kept in enriched enclosures and were fed with bovine meat, whole chicken, rats, supplemented with minerals and vitamins. The anesthetic protocol used was xilazine $(0.9 \mathrm{mg} / \mathrm{kg}, \mathrm{IM}) \mathrm{combined}$ with tiletamine/zolazepan $(6.7 \mathrm{mg} / \mathrm{kg}$, IM). The electroejaculation protocol used was described by Howard (1986) and consisted in 8 series of 10 stimulus, with intensity varying from 2 to 5 volts. Urine contamination was detected in 10 semen samples (31.2\%), being possible to discard these and make good use of the other ones. Values are depicted as mean \pm SEM. The characteristics of the semen were: volume 0.13 $\pm 0.20 \mathrm{ml}$; motility $73.44 \pm 3.71 \%$; status $3.48 \pm 0.11$; $\mathrm{pH} 7.58 \pm 0.07$. Spermatic concentration was $436.41 \pm 95.8 \times 10^{6} \mathrm{cells} / \mathrm{ml}$, with $55.86 \pm 3.34 \%$ morphologically normal spermatozoids. Results demonstrated that the used protocol was efficient in all animals submitted to semen collection and that teratospermia is high in this species.

Key-words: Semen, felids, feline, andrologic examinations, Leopardus tigrinus.

Correspondência para: Renato Herdina Erdmann, Av. Brasil 7640, CEP 85810-001, Cascavel-PR, email:renatoerdmann@yahoo.com.br. 


\section{Introdução}

Populações de animais silvestres de todo o planeta têm sofrido ameaças constantes e a conseqüência direta dessas ameaças é o alto número de espécies ameaçadas de extinção. Jardins zoológicos e outras instituições que fazem reprodução ex situ compartilham a grande responsabilidade de ajudar a prevenir a rápida extinção de espécies silvestres no planeta Terra (MOREIRA, 2001).

O gato-do-mato-pequeno (Leopardus tigrinus) ocorre provavelmente ainda em todo o estado do Paraná, sendo classificado como espécie vulnerável pelo Livro Vermelho da Fauna Ameaçada no Estado do Paraná., publicado em 2004 pelo Instituto Ambiental do Paraná (PARANÁ, 2004).

Uma melhor compreensão da fisiologia reprodutiva dos pequenos felídeos neotropicais faz-se necessária, para um desempenho reprodutivo mais consistente em cativeiro, para aumentar o número de indivíduos que se reproduzem na população e para que técnicas de reprodução assistida sejam aplicadas com maior sucesso (MOREIRA, 2001).

SWANSON et al. (2003) relataram os resultados da colheita de sêmen em 17 machos de gato-do-mato-pequeno em zoológicos latinoamericanos, sendo que dessas colheitas, seis amostras foram criopreservadas para formação de um banco de reserva genômica.

Uma análise descritiva do sêmen determina o volume do ejaculado, $\mathrm{pH}$, porcentagem de motilidade espermática, motilidade progressiva, concentração, morfologia e integridade acrossomal (HOWARD, 1993).

O presente estudo tem como objetivos a descrição de exames andrológicos para a espécie Leopardus tigrinus, mantidos em um criadouro de animais silvestres.

\section{Material e métodos}

O experimento corresponde a uma pesquisa onde descreve-se os parâmetros andrológicos para o gato-do-mato-pequeno (Leopardus tigrinus), mantidos em cativeiro e com dieta à base de carne, frango, pintainhos e suplemento mineral/vitamínico.

A parte experimental deste trabalho foi realizada de setembro de 2004 a janeiro de 2005, no Criadouro de Animais Silvestres da ITAIPU Binacional (CASIB), no município de Foz do Iguaçu - PR, com a seguinte localização geográfica: latitude: $25^{\circ} 32^{\prime}$ sul, longitude: $54^{\circ}$ 53' oeste.

Foram utilizados 11 machos de gato-domato-pequeno (Leopardus tigrinus), adultos, em três séries de colheitas, perfazendo um total de 32 colheitas. Os animais (identificados com microchip) foram numerados GMP 1 à GMP 11.

Foi realizada contenção física com puçá, seguida da pesagem e anestesia, com cloridrato de xilazina $(0,95 \pm 0,26 \mathrm{mg} / \mathrm{kg})$ e 6,7 $\mathrm{mg} / \mathrm{kg}$ de cloridrato de tiletamina/zolazepan; Após a anestesia e perda da consciência e de reações a estímulos externos, todos os animais foram submetidos à criteriosa avaliação clínica e monitoramento anestésico.

Os testículos foram palpados para determinação de consistência, sendo classificados como: a) alterado com presença de fibroses, b) normais com consistência fibroelástica ou c) alterado com consistência mais flácida que a fibroelástica. Foram mensurados o comprimento e a largura testiculares com paquímetro. Para o cálculo do volume total foi utilizada a fórmula $\mathrm{V}=\mathrm{C} \times \mathrm{L}^{2} \mathrm{X}$ 0,524 ; onde $\mathrm{V}=$ volume testicular, $\mathrm{C}=$ comprimento testicular, $\mathrm{L}=$ largura testicular (WILDT et al., 1993). O pênis e o prepúcio foram examinados quanto à morfologia, presença de secreção e de espículas na glande.

O sêmen foi obtido por eletroejaculação, utilizando-se um equipamento para uso em animais selvagens (PT Electronics $\AA$, modelo 303, EUA). O protocolo de eletroejaculação utilizado foi o proposto por HOWARD et al. (1986) consistindo em um total de 80 estímulos elétricos de 2 a $5 \mathrm{~V}$, aplicados em três séries (com 30, 30 e 20 estímulos). Para coletar o sêmen, o pênis do animal era exposto pela aplicação de suave pressão em sua base com um pequeno frasco plástico transparente de 1,5 $\mathrm{ml}$ pré-aquecido. Os frascos coletados permaneciam em suportes de isopor à temperatura ambiente controlada de $20^{\circ} \mathrm{C}$, até a avaliação e processamento. Após o término de cada série, era realizada a avaliação parcial do sêmen quanto ao aspecto (avaliação visual para cor e viscosidade), motilidade (em 
microscópio óptico avaliando-se porcentagem de motilidade progressiva, de 0 a 100), vigor (em microscópio ótico determinando-se índice de 0 a 5), e volume parcial do ejaculado (em micro-pipeta de volume variável de 0 a $100 \mu \mathrm{L}$ ). Ao final da coleta, as alíquotas obtidas com presença de espermatozóides móveis eram combinadas e analisadas para aspecto, volume final, concentração (em câmara de contagem Newbauer), $\mathrm{pH}$ (com fita reagente), motilidade, vigor e morfologia espermática (em microscópio de contraste de fase, com sêmen diluído em solução de formol-citrato), segundo critérios do Colégio Brasileiro de Reprodução Animal (1998).

\section{Resultados e discussão}

Os gatos-do-mato-pequeno apresentaram peso médio de $2,82 \mathrm{~kg}$, dentro da faixa esperada para a espécie (PARANA, 2004), que é de 1,5 a 3,0 kg. No exame clínico foi observado bom estado nutricional dos animais.

$\mathrm{Na}$ avaliação morfológica do aparelho genital, foram encontrados pênis de aspecto normal, com inserção posterior, presença de espículas penianas em todos os animais e ausência de aderências ou frênulo persistente. Segundo MORAIS et al. (2002), estes dados são considerados normais para a espécie e a presença de espículas penianas é indicativa de produção de testosterona pelo indivíduo.

A consistência testicular encontrada na maioria dos animais foi a fibroelástica, com exceção de um indivíduo, que apresentou consistência levemente mais flácida em comparação aos demais. Este animal apresentou a menor média de concentração $\left(31,25 \times 10^{6}\right.$ espermatozóides $\left./ \mathrm{ml}\right)$ e a menor média de espermatozóides viáveis por ejaculado $\left(2,25 \times 10^{6}\right)$ do grupo (TABELA 1$)$.

A média do volume testicular total encontrado nestes animais foi $2,30 \mathrm{~cm}^{3}$. Estes valores estão abaixo dos encontrados por MORAIS et al. $(2002)-\left(4,2 \mathrm{~cm}^{3}\right)$ que trabalharam com animais provenientes do mesmo criadouro deste trabalho, porém próximos das médias descritas por SWANSON et al. (2003) $-\left(2,8 \mathrm{~cm}^{3}\right)$, ao trabalharam com animais de diversos zoológicos Sul-americanos.

Quanto à colheita de sêmen, a mesma foi efetiva em todas as vezes, em que os animais foram submetidos à eletroejaculação. Em relação ao aspecto do ejaculado, observou-se uma variação de translúcida a leitosa, sendo à esta última a mais concentrada. Foram obtidas frações de ejaculado com coloração amarela em $31,2 \%$, das coletas indicando contaminação por urina, confirmando-se pelo $\mathrm{pH}$ com valores inferiores a 7,0. Estas contaminações não inviabilizaram a colheita, pois as alíquotas contaminadas foram descartadas. A contaminação por urina é freqüente em colheitas de sêmen por eletroejaculação em felídeos (MORAIS et al., 2002; TEBET, 2004). Foi observada em algumas amostras, após alguns minutos, uma leve alteração na coloração do sêmen, passando da cor original para uma coloração levemente rósea, observação esta também descrita por TEBET (2004).

$\mathrm{O} \mathrm{pH}$ médio encontrado foi de 7,58 , descartando-se as alíquotas visivelmente contaminadas por urina. $O$ volume médio encontrado foi de 0,13 ml (TABELA 1). Há que se ressaltar que a amplitude dos valores do volume foi elevada, variando de 0,02 a 0,53 $\mathrm{ml}$, com um coeficiente de variação (CV) de $89,5 \%$. Quanto à concentração do ejaculado, obteve-se a média de 436,41 espermatozóides/ $\mathrm{ml}$, estando próxima à descrita por MORAIS et al. (2002).

Os machos de gato-do-mato-pequeno (macho 2, macho 5 e o macho 6) que estavam com fêmeas no recinto apresentaram os maiores números totais de espermatozóides por ejaculado.

No presente trabalho, todas as colheitas realizadas apresentaram espermatozóides, não sendo encontrado nenhum animal azoospérmico. SWANSON et al. (2003) apresentaram em tabelas as amplitudes de concentração seminal de felídeos mantidos em zoológicos latino-americanos, sendo encontrados em quase todas as espécies pesquisadas animais azoospérmicos. 
TABELA 1 -MÉDIAS DO VOLUME DO EJACULADO (VOL), CONCENTRAÇÃO ESPERMÁTICA (CONC.), MOTILIDADE (MOT.), VIGOR, TOTAL DE ESPERMATOZÓIDES POR EJACULADO (TOTAL SP) E NÚMERO DE CÉLULAS VIÁVEIS POR EJACULADO (VIÁVEIS) EM GATO-DO-MATOPEQUENO (Leopardus tigrinus) (GMP). FOZ DO IGUAÇU (PR). ( $\mathrm{N}=32$ COLETAS).

\begin{tabular}{lcccc}
\hline Animal & Vol. $(\mathrm{ml})$ & Conc. $\left(\times 10^{6} / \mathrm{ml}\right)$ & Total sp $\left(\times 10^{6}\right)$ & Viáveis $\left(\times 10^{6}\right)$ \\
\hline MP 1 $\left({ }^{3}\right)$ & $0,10 \pm 0,3$ & $198,33 \pm 33,9$ & $19,27 \pm 7,8$ & $13,69 \pm 8,9$ \\
MP 2 $\left(^{3}\right)$ & $0,16 \pm 0,7$ & $376,83 \pm 236,6$ & $88,57 \pm 74,8$ & $79,01 \pm 67,7$ \\
MP 3 $\left({ }^{3}\right)$ & $0,09 \pm 0,4$ & $304,17 \pm 185,7$ & $39,50 \pm 34,6$ & $34,53 \pm 31,7$ \\
MP 4 $\left(^{3}\right)$ & $0,03 \pm 0,1$ & $632,83 \pm 251,0$ & $24,15 \pm 17,3$ & $20,05 \pm 16,3$ \\
MP 5 $\left({ }^{3}\right)$ & $0,40 \pm 0,9$ & $228,67 \pm 33,1$ & $91,27 \pm 29,3$ & $77,95 \pm 28,2$ \\
MP 6 $\left(^{3}\right)$ & $0,11 \pm 0,4$ & $766,50 \pm 301,7$ & $97,87 \pm 71,5$ & $86,32 \pm 65,2$ \\
MP 7 $\left({ }^{3}\right)$ & $0,09 \pm 0,1$ & $416 \pm 143,2$ & $42,93 \pm 18,5$ & $37,19 \pm 15,8$ \\
MP 8 $\left(^{3}\right)$ & $0,11 \pm 0,2$ & $129,17 \pm 68,7$ & $14,50 \pm 7,6$ & $11,09 \pm 6,5$ \\
MP 9 $\left(^{3}\right)$ & $0,04 \pm 0,5$ & $1441,33 \pm 674,3$ & $63,77 \pm 35,3$ & $50,67 \pm 28,5$ \\
MP 10 $\left({ }^{3}\right)$ & $0,21 \pm 0,45$ & $140,33 \pm 65,5$ & $29,33 \pm 15,8$ & $23,71 \pm 12,6$ \\
MP 11 $(2)$ & $0,10 \pm 0,2$ & $31,25 \pm 27,3$ & $3,80 \pm 3,5$ & $2,25 \pm 2,1$ \\
\hline Médias $( \pm$ EPM) & $0,13 \pm 0,2$ & $436,41 \pm 95,8$ & $48,16 \pm 11,1$ & $40,85 \pm 10,0$ \\
\hline
\end{tabular}

A motilidade média observada foi de $73,44 \%$, com um vigor médio de 3,48 (IMP). Com estes valores foi calculado o Índice de motilidade progressiva, que é dado pela fórmula:

$$
\text { IMP }=(\text { Mot \% }+(\text { Vig } \times 20)) / 2
$$

onde Mot é a porcentagem de espermatozóides móveis e Vig é o vigor espermático.

Comparando-se os valores médios do IMP 69,39, observa-se que o valor encontrado é inferior aos descritos por TEBET $(2004)$ - $(79,3)$ e MORAIS et al. (2002) - $(74,1)$, porém estão acima das médias descritas por SWANSON et al. (2003) que foi de 62,1. Vale ressaltar que os valores descritos por SWANSON et al. (2003) para esta e demais variáveis, representam a média de indivíduos investigados em diversos zoológicos da América Latina, em um número de 17 machos de gato-do-mato-pequeno.

TABELA 2 - MORFOLOGIA ESPERMÁTICA EM GATO-DO-MATO-PEQUENO (Leopardus tigrinus) MÉDIA ( \pm EPM). ( $N=32$ COLETAS DE 11 ANIMAIS).

\begin{tabular}{lc}
\hline & Médias (\%) \\
\hline Espermatozóides normais & $55,86 \pm 3,3$ \\
\hline Cabeça contorno anormal & $2,45 \pm 0,5$ \\
Cabeça delgada & $1,70 \pm 0,4$ \\
Cabeça gigante & $1,11 \pm 0,2$ \\
Cauda enrolada na cabeça & $1,41 \pm 0,2$ \\
Cauda fortemente dobrada/enrolada & $13,17 \pm 2,3$ \\
Defeito de acrossomo & $2,24 \pm 0,4$ \\
Defeito em peça intermediária & $5,05 \pm 0,8$ \\
Gota citoplasmática proximal & $1,98 \pm 0,4$ \\
Microcefalia & $0,23 \pm 0,1$ \\
Teratogênicos & $0,82 \pm 0,7$ \\
Cabeça isolada & $3,12 \pm 0,6$ \\
Cauda dobrada c/ gota & $1,32 \pm 0,4$ \\
Cauda dobrada/enrolada & $5,35 \pm 0,6$ \\
Gota citoplasmática distal & $3,26 \pm 1,1$ \\
Inserção anormal & $0,94 \pm 0,2$ \\
\hline Total de defeitos (\%) & $44,14 \pm 3,2$ \\
\hline
\end{tabular}


A avaliação morfológica dos espermatozóides presentes nos ejaculados foi realizada em todas as colheitas seminais realizadas. Foram encontradas quantidades significativas de defeitos morfológicos em espermatozóides avaliados (44,1\% em média). A incidência de pleiomorfismo entre as três espécies ( $L$ tigrinus, $L$ wiedii e $L$. pardalis) é alta; entretanto as anormalidades específicas diferem entre as espécies (MORAIS et al., 2002).

A despeito da alta incidência de teratozoospermia em felídeos selvagens, há poucas informações sobre as causas ou implicações funcionais desta característica (PUKAZHENTHI et al., 2001).

\section{Conclusões}

Os parâmetros reprodutivos encontrados nos animais pesquisados são compatíveis com os relatados por outros autores, estando dentro das amplitudes de valores descritas para esta espécie.

Existe variação individual nas características seminais entre os machos desta espécie.

O índice de alterações de morfologia espermática nesta espécie é alto.

Os valores dos parâmetros seminais podem servir de base para pesquisa aplicada em animais desta espécie, mantidos em cativeiro.

\section{Agradecimentos}

Ao CNPq pelo apoio financeiro e a ITAIPU Binacional que disponibilizou os animais para esta pesquisa.

\section{REFERÊNCIAS}

COLÉGIO BRASILEIRO DE REPRODUÇÃO ANIMAL. Manual para exame andrológico e avaliação de sêmen animal. 2. ed. Belo Horizonte, 1998.

Recebido para publicação: 28/06/2005

Aprovado:

$25 / 10 / 2005$
HOWARD, J.G. Semen collection and analysis in nondomestic carnivores. In: Zoo and Wild Animal Medicine III, p. 390-399. Ed. ME Fowler. WB Saunders Co, Philadelphia, 1993.

HOWARD, J.G.; BUSH, M.; WILDT, D.E. Semen collection, analysis and cryopreservation in nondomestic mammals. In: MORROW, D.A. Current Therapy in Theriogenology. 2. ed. Philadelphia: W.B. Saunders, 1986, p.1047-1053.

MORAIS, R.N.; MUCCIOLO, R.G.; GOMES, M.L.F.; LACERDA, O.; MORAES, W.; MOREIRA, N.; GRAHAM, L.H.; SWANSON, W.F.;BROWN, J.L. Seasonal analysis of semen characteristics, serum testosterone and fecal androgens in the ocelot (Leopardus pardalis), margay ( $L$. wiedii) and tigrina (L. tigrinus). Theriogenology, New York, p.2027-2041, 2002.

MOREIRA, N. Reprodução e estresse em fêmeas de felídeos do gênero Leopardus. Curitiba, 2001. Tese (Doutorado) - Universidade Federal do Paraná.

PARANÁ. Instituto Ambiental do Paraná - 2004, disponível em: http://celepar7.pr.gov.br/livrovermelho/ index. asp? idgrupo $=4 \&$ idmenu $=$ VU\&idespecie $=242$ (acesso em 19/04/2005)

PUKAZHENTHI, B.S.; WILDT, D.E.; HOWARD, J.G. The phenomenon and Significance of Teratospermia in Felids. Journal of Reproduction and Fertility, Cambridge, v. 57, p. 423-433, 2001.

SWANSON, W.F.; JOHNSON, W.E.; CAMBRE, R.C. Reproductive status of endemic felid species in Latin American zoos and implications for ex situ conservation. Zoo Biology, New York, v. 22, p. 421441, 2003.

TEBET, M.J. Efeito da criopreservação sobre a célula espermática em três espécies de felinos: O gato-do-mato-pequeno (Leopardus tigrinus), a jaguatirica (Leopardus pardalis) e o gato doméstico (Felis catus). Botucatu, 2004. Tese (Doutorado) - Universidade Estadual Paulista "Julio de Mesquita Filho".

WILDT, D.E.; BUSH, M.; O'BRIEN, S.J. Training Manual: reproduction, genetics and veterinary medicine. Front Royal: Center for New Opportunities in Animal Health Sciences (NOAHS), Conservation and Research Center, National Zoo, Smithsonian Institution, 1993. 